FLUID MECHANICS 
Also from Macmillan Education

Engineering Thermodynamics

Theory, worked examples and problems

G. Boxer

Introduction to Engineering Fluid Mechanics,

Second Edition

J. Fox

Principles of Engineering Thermodynamics

E. M. Goodger 


\title{
FLUID MECHANICS
}

Theory, worked examples and problems

\author{
H. C. Lowe
}

Principal Lecturer,

Department of Mechanical and Civil Engineering,

North Staffordshire Polytechnic 
(C) H.C. Lowe 1979

All rights reserved. No part of this publication may be reproduced or transmitted, in any form or by any means, without permission.

First published 1978 by

THE MACMILLAN PRESS LTD

London and Basingstoke

Associated Companies in Delhi Dublin

Hong Kong Johannesburg Lagos Melbourne

New York Singapore and Tokyo

British Library Cataloguing in Publication Data

Lowe, $\mathrm{HC}$

Fluid Mechanics.

1. F1uid mechanics

I. Title

532

QC145.2

ISBN 978-1-349-03922-7

ISBN 978-1-349-03920-3 (eBook)

DOI 10.1007/978-1-349-03920-3

This book is sold subject to the standard conditions of the Net Book Agreement.

The paperback edition of this book is sold subject to the condition that it shall not, by way of trade or otherwise, be lent, resold, hired out, or otherwise circulated without the publisher's prior consent in any form of binding or cover other than that in which it is published and without a similar condition including this condition being imposed on the subsequent purchaser. 


\section{CONTENTS}

Preface vii

Symbols and Units ix

1 FUNDAMENTAL CONCEPTS 1

1.1 Characteristics of Fluids 1

1.2 Dimensions and Units 1

1.3 Force 3

1.4 Surface Stresses 4

1.5 Laminar and Turbulent Flow 6

$\begin{array}{lll}1.6 & \text { Thermodynamic Concepts } & 7\end{array}$

$\begin{array}{lll}1.7 & \text { Properties of Fluids } & 9\end{array}$

$\begin{array}{lll}1.8 & \text { Equation of State } & 11\end{array}$

$\begin{array}{ll}1.9 \text { Velocity of Propagation of an } & \\ \text { Infinitesimal Pressure Disturbance } & 12\end{array}$

2 STATICS OF FLUIDS 24

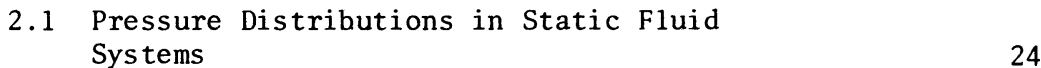

2.2 Pressure Distribution in a Fluid of
Variable Density

2.3 Pressure Distribution in an
Accelerating Fluid System

2.4 Forces on Solid Surfaces Immersed in Fluids 28

$\begin{array}{llr}2.5 & \text { Buoyancy Forces } & 29\end{array}$

3 KINEMATICS OF FLUID FLOW 48

3.1 Flow Fields 48

3.2 Flow Lines 49

3.3 Acceleration $\quad 50$

3.4 Conservation of Mass and the 51

3.5 The Stream Function 52

3.6 Circulation, Vorticity and Rotation 53

3.7 Velocity Potential Function 55

3.8 Solution of Flow Patterns $\quad 56$ 
4 DYNAMICS OF FLUID FLOW $\quad 69$

4.1 Conservation of Momentum $\quad 69$

4.2 Equations of Motion 69

4.3 The Bernoulli Equation $\quad 70$

4.4 The Momentum Theorem $\quad 74$

$\begin{array}{lll}4.5 & \text { Angular Momentum } & 76\end{array}$

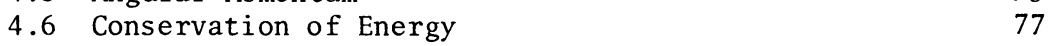

4.7 Relationship between the Euler, Bernoulli
and Steady-Flow Energy Equations

5 DIMENSIONAL ANALYSIS AND MODEL TESTING 110

5.1 Dimensional Analysis $\quad 110$

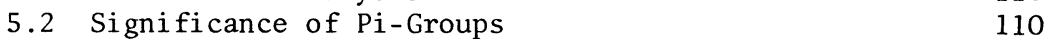

5.3 Similarity and Mode1 Testing 112

$\begin{array}{ll}5.4 & \text { Similarity from Basic Differential } \\ \text { Equations } & 115\end{array}$

6 FLOW OVER BODIES 131

6.1 Characteristics of Real Fluid Flow 131

6.2 Incompressible Flow Around Bodies 134

7 FLOW IN DUCTS 156

7.1 Characteristics of Flow in Circular Pipes 156

7.2 Friction Losses in Ducts 157

$\begin{array}{lll}7.3 & \text { Minor Losses } & 160\end{array}$

$\begin{array}{lll}7.4 & \text { Pipe Systems } & 160\end{array}$

$\begin{array}{ll}7.5 & \begin{array}{l}\text { Effect of Non-Uni form Velocity } \\ \text { Distribution }\end{array} \\ \end{array}$

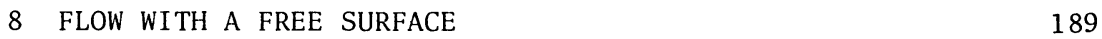

8.1 Characteristics of Flow in Open Channels 189

8.2 Uni form Flow 190

8.3 Velocity of Propagation of a Surface Wave 191

8.4 Specific Head 192

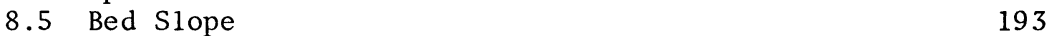

8.6 Surface Profile 193

$\begin{array}{lll}9 & \text { UNSTEADY FLOW } & 210\end{array}$

9.1 Pulsating Flow 210

9.2 Quasi-Steady Flow 211

9.3 Flow with Significant Acceleration Forces 211

9.4 Flow with Significant Elastic Forces 211

$\begin{array}{lr}\text { Bibliography } & 228\end{array}$ 


\section{PREFACE}

The purpose of this book is to present the fundamental laws of fluid mechanics and illustrate them by application to a wide range of worked examples and problems.

The level is suitable for first and some second year fluid mechanics work on degree and diploma courses in mechanical and civil engineering. The book should also be userul to students preparing for CEI examinations.

The presentation is based on a logical teaching order in preference to grouping the examples under convenient topic headings. A feature of the book is the rigorous treatment of fundamentals in the introductory theory to each chapter. This is necessary because of the wide range of principles involved in fluid mechanics and my belief that the assumptions, on which the principles are based, should be examined. It is also important to consider the range of validity of derived relationships before they are applied to the worked examples.

The actual derivation of the relationships is not considered appropriate in this book and the practice of deriving basic theory in the examples is generally avoided, although there are occasions when it is desirable to link a particular aspect of derived theory with numerical work. It is assumed that the reader will cover the derivations in the lectures of an engineering course, or refer to the books listed in the bibliography.

I attach great importance to the link between certain topics covered in both fluid mechanics and a parallel course in thermodynamics. For this reason, thermodynamic concepts are summarised in Chapter 1. The principle of conservation of energy is treated in Chapter 4 and the important relationship between the Bernoulli equation and the steady-flow energy equation is discussed in detail.

In some chapters, the general three-dimensional flow case is treated, even though the subsequent discussion and examples are restricted to one or two-dimensional flow. This treatment is included for the benefit of students proceeding to an advanced study of fluid mechanics.

Vector methods are used in certain topics, particularly those in the chapter on the dynamics of fluids. Vectors are now taught at an early level and a modern book on fluid mechanics should include vector treatment where appropriate. However, the reader who is unfamiliar with vectors, or the student who prefers to avoid them, should have little difficulty in following the theory and worked 
examples. Scalar equations are always given, in addition to vector equations, and the majority of the examples are solved using scalars.

It is customary in books to denote vector quantities by boldface type. This is impossible in the present work and vector quantities are denoted by an underscore. For example, F denotes a scalar force and $F$ denotes a vector force.

The notation adopted for velocity is particularly important because it is necessary to distinguish between resultant vector velocities in two and three-dimensional flow, and mean velocities used in one-dimensional flow. The symbol used for velocity, throughout this book, is $u$. The resultant vector velocity at a point is $u$, with $u, v$ and $w$ as velocity components in the $x, y$ and $z$-directions, respectively. The mean velocity in duct or channel flow $(\dot{V} / A)$ is denoted by $\bar{u}$. Other velocities are defined by an appropriate subscript e.g. $u_{r}$ and $u_{\theta}$ are radial and tangential velocity components, respectively.

The symbols used in this book conform wherever possible to the recommendations of the British Standards Institution and the Royal Society. All problems are set in SI units and the general method of numerical solution involves the substitution in physical equations of base SI units (i.e. $\mathrm{kg}, \mathrm{m}, \mathrm{N}$, etc.) and multiples of ten. This method obviates the need for any special techniques such as the Stroud convention.

My thanks are due to the Director of the North Staffordshire Polytechnic and the Council of Engineering Institutions for permission to include questions from their examination papers. I arcept sole responsibility for the solutions to the questions.

I wish to express my gratitude to Mrs Kay White for her expert typing of the manuscript and her patient interpretation of my rough notes.

Finally, I wish to thank my wife and children for their encouragement and help during the writing of the manuscript. 


\section{SYMBOLS AND UNITS}

\section{Symbol Quantity}

\begin{tabular}{l} 
A \\
A \\
\hline $\mathrm{a}$ \\
$\mathrm{a}$ \\
$\mathrm{a}$ \\
$\mathrm{B}$ \\
$\mathrm{b}$ \\
$\mathrm{C}$ \\
$\mathrm{C}$ \\
$\mathrm{C}$ \\
$\mathrm{C}$ \\
$\mathrm{C}$ \\
$\mathrm{C}$ \\
$\mathrm{C}$ \\
$\mathrm{C}$ \\
$\mathrm{C}$
\end{tabular}

$c_{f}$

$c_{p}$

c v

D

$\mathrm{D}_{\mathrm{e}}$

d

E

$\mathrm{E}_{\mathrm{k}}$

E

e

$\mathrm{F}$

F

$F_{D}$

$\mathrm{F}_{\mathrm{L}}$

Fr

$f$

$\mathrm{g}$

$\mathrm{H}$

$\mathrm{H}_{\mathrm{O}}$

$\mathrm{H}_{\mathbf{S}}$

area

diameter

force

enthalpy area (vector)

linear acceleration

radius of circular cylinder

sonic velocity

width of liquid surface

breadth of weir, spillway, etc.

a constant

Chézy coefficient

contraction coefficient

drag coefficient

discharge coefficient

mean skin coefficient

lift coefficient

velocity (celerity) of wave

propagation

local skin friction coefficient

specific heat at constant pressure

specific heat at constant volume

equivalent diameter (4A/P)

differential operator

internal energy

kinetic energy

potential energy

specific internal energy

force (vector)

drag force

lift force

Froude number $\mathrm{u} / \sqrt{ }(\mathrm{gL})$

friction factor

frequency of vortex shedding

acceleration of free fall

Bernoulli head $\left(p / \rho g+\bar{u}^{2} / 2 g+z\right.$

specific head $\left(\bar{u}^{2} / 2 g+y\right)$
$\mathrm{kJ} / \mathrm{kg} \mathrm{K}$

Preferred Units

$\mathrm{m}^{2}$

$\mathrm{m}^{2}$

$\mathrm{m} / \mathrm{s}^{2}$

$\mathrm{m}$

$\mathrm{m} / \mathrm{s}$

$\mathrm{m}$

m

$\mathrm{m} / \mathrm{s}$

$\mathrm{kJ} / \mathrm{kg} \quad \mathrm{K}$

m

m

kJ

$\mathrm{kJ}$

$\mathrm{kJ}$

$\mathrm{kJ} / \mathrm{kg}$

$\mathrm{N}$

$\mathrm{N}$

N

$\mathrm{N}$

$s^{-1}$

$\mathrm{m} / \mathrm{s}^{2}$

$\mathrm{kJ}$

m

m 


\begin{tabular}{|c|c|c|}
\hline $\begin{array}{l}\mathrm{h} \\
\mathrm{h} \\
\mathrm{K}\end{array}$ & $\begin{array}{l}\text { specific enthalpy } \\
\text { depth below free surface of liquid } \\
\text { a constant }\end{array}$ & $\begin{array}{l}\mathrm{kJ} / \mathrm{kg} \\
\mathrm{m}\end{array}$ \\
\hline $\mathrm{K}_{\mathrm{S}}$ & isentropic bulk modulus & $\mathrm{Pa} \equiv\left(\mathrm{N} / \mathrm{m}^{2}\right)$ \\
\hline $\mathrm{K}_{\mathrm{T}}^{\mathrm{S}}$ & isothermal bulk modulus & $\mathrm{Pa}$ \\
\hline $\mathrm{k}$ & surface roughness height & $\mathrm{m}$ \\
\hline $\mathrm{L}$ & length & $\mathrm{m}$ \\
\hline$\ell$ & length & $\mathrm{m}$ \\
\hline $\ln$ & natural logarithm (i.e. to base e) & \\
\hline $\log$ & logarithm to base 10 & \\
\hline$M$ & total mass & $\mathrm{kg}$ \\
\hline$M$ & Mach number $\mathrm{u} / \mathrm{a}$ & \\
\hline m & $\operatorname{mass}$ & $\mathrm{kg}$ \\
\hline $\mathrm{m}$ & mass flow rate & $\mathrm{kg} / \mathrm{s}$ \\
\hline $\mathrm{m}$ & strength of source or sink $(Q / 2 \pi)$ & $\mathrm{m}^{2} / \mathrm{s}$ \\
\hline $\mathrm{N}$ & rotational speed & $\mathrm{rev} / \mathrm{min}$ \\
\hline $\mathrm{n}$ & rotational speed & $\mathrm{rad} / \mathrm{s}$ \\
\hline $\mathrm{n}$ & frequency of vortex shedding & $s^{-1}$ \\
\hline $\mathrm{n}$ & Manning roughness coefficient & \\
\hline $\mathrm{n}$ & polytropic index & \\
\hline $\mathrm{P}$ & wetted perimeter & $\mathrm{m}$ \\
\hline $\mathrm{P}$ & power & $\mathrm{W}$ \\
\hline $\mathrm{p}$ & pressure & $\mathrm{Pa} \equiv\left(\mathrm{N} / \mathrm{m}^{2}\right)$ \\
\hline $\mathrm{p}_{\mathrm{a}}$ & atmospheric pressure & $\mathrm{Pa}$ \\
\hline $\mathrm{p}^{*}$ & piezometric pressure $(p+\rho g z)$ & $\mathrm{Pa}$ \\
\hline$?$ & flow per unit depth (source or sink) & $\mathrm{m}^{2} / \mathrm{s}$ \\
\hline$?$ & quantity of heat & $\mathrm{kJ}$ \\
\hline O & heat flow rate & $\mathbb{W}$ \\
\hline a & heat per mass & $\mathrm{J} / \mathrm{kg}$ \\
\hline $\mathrm{R}$ & radius & \\
\hline $\mathrm{R}$ & characteristic gas constant & $\mathrm{kJ} / \mathrm{kg} \mathrm{K}$ \\
\hline $\mathrm{Re}$ & Reynolds number ouL/ $\mu$ & \\
\hline $\mathrm{R}_{\mathrm{h}}$ & hydraulic radius $(A / P)$ & $\mathrm{m}$ \\
\hline $\mathrm{r}$ & coordinate & $\mathrm{m}$ \\
\hline $\mathrm{r}$ & radius & $\mathrm{m}$ \\
\hline$\underline{r}$ & radius (vector) & $\mathrm{m}$ \\
\hline S & entropy & $\mathrm{kJ} / \mathrm{K}$ \\
\hline $\mathrm{S}_{\mathrm{O}}$ & slope of channel bed & \\
\hline $\mathrm{S}_{\mathrm{W}}$ & slope of liquid surface & \\
\hline$S$ & slope of energy line & \\
\hline $\mathrm{S}$ & control surface & \\
\hline s & specific entropy & $\mathrm{kJ} / \mathrm{kg} \mathrm{K}$ \\
\hline $\mathrm{T}$ & thermodynamic temperature & \\
\hline $\mathrm{T}$ & torque & $\mathrm{N} \mathrm{m}$ \\
\hline $\mathrm{T}$ & thrust & $\mathrm{N}$ \\
\hline$t$ & time & $\mathrm{s}$ \\
\hline $\mathrm{U}$ & free stream velocity & $\mathrm{m} / \mathrm{s}$ \\
\hline$\underline{U}$ & body velocity (vector) & $\mathrm{m} / \mathrm{s}$ \\
\hline$\underline{\mathrm{u}}$ & fluid velocity (vector) & $\mathrm{m} / \mathrm{s}$ \\
\hline$\overline{\mathrm{u}}$ & mean fluid velocity & $\mathrm{m} / \mathrm{s}$ \\
\hline $\mathrm{u}$ & a fluid velocity & $\mathrm{m} / \mathrm{s}$ \\
\hline $\mathrm{u}$ & fluid velocity component & $\mathrm{m} / \mathrm{s}$ \\
\hline
\end{tabular}




\begin{tabular}{|c|c|c|}
\hline $\mathrm{u}_{\mathrm{a}}$ & axial component of velocity & $\mathrm{m} / \mathrm{s}$ \\
\hline $\mathrm{u}_{\mathrm{R}}$ & relative velocity & $\mathrm{m} / \mathrm{s}$ \\
\hline$u_{\mathrm{r}}$ & radial component of velocity & $\mathrm{m} / \mathrm{s}$ \\
\hline $\mathrm{u}_{\mathrm{S}}$ & $\begin{array}{l}\text { fluid velocity relative to control } \\
\text { surface }\end{array}$ & $\mathrm{m} / \mathrm{s}$ \\
\hline $\mathrm{u}_{\theta}$ & tangential component of velocity & $\mathrm{m} / \mathrm{s}$ \\
\hline $\mathrm{u}_{\mathrm{v}}$ & $\begin{array}{l}\text { fluid velocity relative to control } \\
\text { volume }\end{array}$ & $\mathrm{m} / \mathrm{s}$ \\
\hline$u_{w}$ & whirl component of velocity & $\mathrm{m} / \mathrm{s}$ \\
\hline $\begin{array}{l}\mathrm{V} \\
\mathrm{V}\end{array}$ & $\begin{array}{l}\text { a volume } \\
\text { control volume }\end{array}$ & $\mathrm{m}^{3}$ \\
\hline V & volumetric flow rate & $\mathrm{m}^{3} / \mathrm{s}$ \\
\hline $\mathrm{v}$ & fluid velocity component ( $y$-direction) & 1) $\mathrm{m} / \mathrm{s}$ \\
\hline$u$ & specific volume & $\mathrm{m}^{3} / \mathrm{kg}$ \\
\hline W & work & $\mathrm{J}$ \\
\hline We & Weber number $u \sqrt{ }(\rho L / \gamma)$ & \\
\hline$W_{x}$ & shaft or electrical work & $\mathrm{J}$ \\
\hline w & work per mass & $\mathrm{J} / \mathrm{kg}$ \\
\hline w & fluid velocity component (z-direction) & $\mathrm{m} / \mathrm{s}$ \\
\hline $\mathrm{x}$ & coordinate & $\mathrm{m}$ \\
\hline $\mathrm{y}$ & depth of liquid (channel flow) & $\mathrm{m}$ \\
\hline $\mathrm{y}$ & coordinate & $\mathrm{m}$ \\
\hline$z$ & height above arbitrary datum & $\mathrm{m}$ \\
\hline$z$ & coordinate & $\mathrm{m}$ \\
\hline
\end{tabular}

Greek symbols

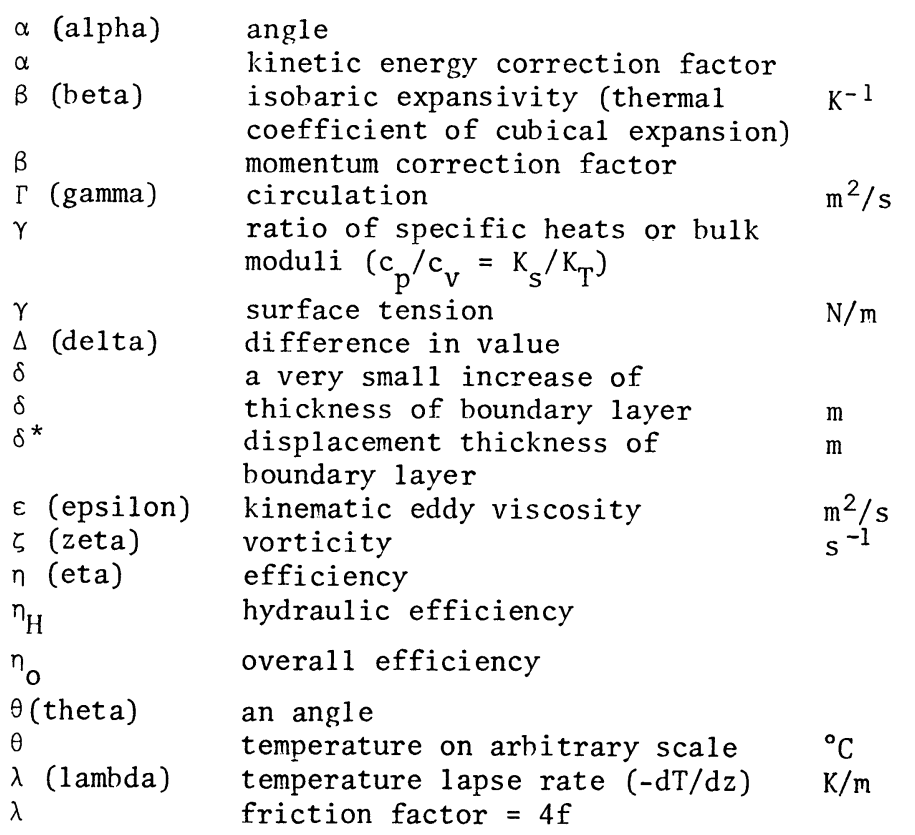




\begin{tabular}{|c|c|c|}
\hline \multicolumn{3}{|c|}{ dynamic viscosity } \\
\hline \multirow{5}{*}{$\begin{array}{l}\text { (nu) } \\
(\mathrm{pi}) \\
(\text { rho) } \\
\text { (sigma) }\end{array}$} & kinematic viscosity $(\mu / \rho)$ & $\mathrm{m}^{2} / \mathrm{s}$ \\
\hline & dimensionless parameter & \\
\hline & $3.14159 \ldots$ & \\
\hline & mass density & $\mathrm{kg} / \mathrm{m}^{3}$ \\
\hline & summation & \\
\hline$\sigma$ & normal stress & $\mathrm{Pa}$ \\
\hline (tau) & shear stress & $\mathrm{Pa}$ \\
\hline$\tau_{0}$ & shear stress at houndary & $\mathrm{Pa}$ \\
\hline $\begin{array}{l}\phi \quad \text { phi) } \\
\phi \\
\psi(\text { psi) } \\
\omega \text { (omega) }\end{array}$ & $\begin{array}{l}\text { a function of } \\
\text { velocity potential function } \\
\text { stream function } \\
\text { angular velocity }\end{array}$ & $\begin{array}{l}\mathrm{m}^{2} / \mathrm{s} \\
\mathrm{m}^{2} / \mathrm{s} \\
\mathrm{rad} / \mathrm{s}\end{array}$ \\
\hline \multicolumn{3}{|l|}{ Suffixes } \\
\hline $\begin{array}{l}c \\
d\end{array}$ & critical & \\
\hline $\begin{array}{l}\mathrm{d} \\
\mathrm{R}\end{array}$ & delivery & \\
\hline $\mathrm{R}$ & relative to & \\
\hline & suction & \\
\hline$S$ & relative to control surface & \\
\hline & relative to control volume & \\
\hline \multirow{2}{*}{$\begin{array}{ll}x, y \\
0 \\
1,2\end{array}$} & $\begin{array}{l}\text { component of vector quantity in } x \text {, } \\
\text { stagnation conditions }\end{array}$ & $y, z$ directions \\
\hline & $\begin{array}{l}\text { at inlet or outlet of control volum } \\
\text { at a large distance upstream from }\end{array}$ & $\begin{array}{l}\text { ne or machine rotor } \\
\text { body }\end{array}$ \\
\hline
\end{tabular}

